\title{
Aspectos culturais relacionados ao aleitamento materno exclusivo em puérperas atendidas em alojamento conjunto
}

\author{
Cultural aspects related to exclusive breastfeeding in postpartum women held in \\ joint accommodation
}

\section{Aspectos culturales relacionados con la lactancia materna exclusiva en puérperas realizadas en alojamiento conjunto}

Flávia Moraes Pacheco da Silva ${ }^{1}$, Heliana Helena de Moura Nunes ${ }^{1}$, Juliane Moreira de Almeida ${ }^{1}$, Leticia Diogo Moura de Menezes ${ }^{1}$, Ana Carla Barbosa Figueiredo ${ }^{2}$, Anna Thalita de Souza Cardoso ${ }^{3}$, lanny Ferreira Raiol ${ }^{4 *}$, Jaqueline Cardoso Marcena ${ }^{4}$, Juliana Conceição Dias Garcez ${ }^{4}$.

\section{RESUMO}

Objetivo: Entender a influência dos aspectos culturais relacionados ao Aleitamento Materno Exclusivo (AME) em puérperas atendidas no Alojamento Conjunto (ALCON) em um hospital de referência de materno infantil. Métodos: Trata-se de um estudo de campo, de caráter qualitativo. Foram entrevistadas 20 puérperas, com idade entre 18 a 36 anos, a partir de um questionário com perguntas semiestruturadas subdivididas em duas sessões: A primeira sessão com questões relacionadas à caracterização do perfil sociodemográfico das puérperas; A segunda com perguntas abertas referentes aos aspectos culturais em relação ao $\mathrm{AME}$, onde seus dados foram tratados no software Iramuteq ${ }^{\circledR}$. A pesquisa foi aprovada pelo Comitê de Ética e Pesquisa $\mathrm{n}^{\circ}$ 4.568.359. Resultados: As ramificações geradas pelo software foram redefinidas em 3 categorias IAspectos relacionados a Amamentação; II Aspectos relacionados as orientações recebidas durante o prénatal; III- Aspectos relacionados as orientações recebidas pelos familiares; que possibilitaram entender a influência cultural que as puérperas possuem, independente de idade, escolaridade, ocupação, religião e estado civil. Conclusão: O enfermeiro deve, em suas consultas no ALCON, valorizar esses conhecimentos culturais mediante a teoria transcultural voltando a realidade de cada puérpera no sentido de fazer com que os saberes tradicionais sejam discutidos e levados em consideração.

Palavras-chave: Aleitamento materno, Aspectos culturais, Alojamento conjunto.

\begin{abstract}
Objective: To understand the influence of cultural aspects related to Exclusive Breastfeeding (EBF) in puerperal women assisted in the Rooming-in (ALCON) in a reference hospital for maternal and child care. Methods: This is a qualitative field study. Twenty puerperal women, aged between 18 and 36 years, were interviewed using a questionnaire with semi-structured questions divided into two sessions: The first session with questions related to the characterization of the sociodemographic profile of the puerperal women; The second with open questions referring to cultural aspects in relation to EBF, where their data were processed in the Iramuteg® software. The research was approved by the Research Ethics Committee No. 4,568,359. Results: The ramifications generated by the software were redefined in 3 categories I- Aspects related to Breastfeeding; II Aspects related to guidance received during prenatal care; III- Aspects related to guidance received by family members; that made it possible to understand the cultural influence that the puerperal women have, regardless of age, schooling, occupation, religion and marital status. Conclusion: Nurses should, in their consultations at ALCON, value this cultural knowledge through the transcultural theory, returning to the reality of each puerperal woman in order to ensure that traditional knowledge is discussed and taken into account.
\end{abstract}

Keywords: Breastfeeding, Cultural aspects, Joint accommodation.

\footnotetext{
${ }^{1}$ Universidade do Estado do Pará (UEPA), Belém - PA.

${ }^{2}$ Fundação Santa Casa de Misericórdia do Pará, Belém - PA.

${ }^{3}$ Faculdade Pan Amazônica (FAPAN), Belém - PA.

${ }^{4}$ Centro Universitário Metropolitano da Amazônia (UNIFAMAZ), Belém - PA. *E-mail: raiolianny@hotmail.com
} 


\section{RESUMEN}

Objetivo: Comprender la influencia de los aspectos culturales relacionados con la Lactancia Materna Exclusiva (LME) en puérperas atendidas en Alojamiento Conjunto (ALCON) en un hospital de referencia para la atención maternoinfantil. Métodos: Este es un estudio de campo cualitativo. Veinte puérperas, con edades entre 18 y 36 años, fueron entrevistadas mediante un cuestionario con preguntas semiestructuradas divididas en dos sesiones: La primera sesión con preguntas relacionadas con la caracterización del perfil sociodemográfico de las puérperas; El segundo con preguntas abiertas referentes a aspectos culturales en relación a la LME, donde sus datos fueron procesados en el software Iramuteq ${ }^{\circledR}$. La investigación fue aprobada por el Comité de Ética en Investigación $N^{\circ}$ 4.568.359. Resultados: Las ramificaciones generadas por el software fueron redefinidas en 3 categorías I- Aspectos relacionados con la Lactancia Materna; II Aspectos relacionados con la orientación recibida durante la atención prenatal; III- Aspectos relacionados con la orientación recibida por los familiares; que permitió comprender la influencia cultural que tiene la puérpera, independientemente de su edad, escolaridad, ocupación, religión y estado civil. Conclusión: El enfermero debe, en su consulta en ALCON, valorizar este saber cultural a través de la teoría transcultural, volviendo a la realidad de cada puérpera para que los saberes tradicionales sean discutidos y tenidos en cuenta.

Palabras clave: Amamantamiento, Aspectos culturales, Alojamiento conjunto.

\section{INTRODUÇÃO}

A amamentação é um processo de profunda interação entre mãe e o bebê que envolve tanto a afetividade quanto repercussões no estado nutricional da criança, fortalecendo a habilidade da mesma na defesa contra infecções, em sua fisiologia, e em seu desenvolvimento cognitivo e emocional, além de gerar benefícios na saúde física e psíquica da mãe (OLIVEIRA RAM, et al., 2018).

No entanto, no período de amamentação, as mães encontram-se em dúvidas em relação a tomada de decisão, pois não sabem se seguem as orientações dadas pelos profissionais em saúde ou se seguem os saberes tradicionais dos avós ou familiares, podendo influenciar no processo de AME (FERREIRA TDM, et al., 2018).

Assim, destaca-se a importância da atuação do enfermeiro no ALCON, por ser o ambiente em que a mãe e o recém-nascido (RN) permanecem juntos enquanto ambos estiverem na maternidade, sendo responsabilidade da equipe de enfermagem as orientações e informações imprescindíveis, a saber: coloração da pele, coto umbilical, capacidade de sucção, sinais vitais ou estado geral; higiene corporal, cuidados com as mamas, alimentação, sono e repouso, pega correta, posição para amamentação e a realização da escuta ativa da mulher em relação aos medos, ansiedade e preocupações para que não retorne a sua residência insegura e preocupada (FEDERAÇÃO BRASILEIRA DAS ASSOCIAÇÕES DE GINECOLOGIA E OBSTETRÍCIA (FEBRASGO), 2018).

O cuidado em trazer um caráter humanitário para o campo da enfermagem é realidade desde a década de 60, quando Leininger desenvolveu a Teoria da Diversidade e Universalidade que buscava relacionar os conhecimentos do campo da enfermagem com os da antropologia cultural, apresentando um novo modo de diagnosticar e compreender o paciente a partir do entendimento dos costumes e práticas de cada cultura, emergindo com isso a Teoria Transcultural (LEININGER M, 2002).

Nesse sentido, a Teoria Transcultural destaca-se como a possibilidade de relacionar a prática do aleitamento materno a partir do conhecimento cientifico e humanizado, adequando práticas cientificas universais em culturas específicas, dando subsídios ao enfermeiro orientar a puérpera acerca da importância da amamentação e da compreensão dos saberes tradicionais durante a amamentação de seus filhos (MOURA MAV, et al., 2005).

Dessa forma, na atual conjuntura, inúmeras pesquisas voltadas a esta teoria versam acerca da importância de se levantar os saberes de cada cultura com as práticas de enfermagem: Lucena TS (2019), em um estudo realizado na comunidade quilombola remanescente Muquén (CRQM) no estado de Alagoas buscou levantar as práticas de cuidados das puérperas no período do pós-parto a partir da teoria transcultural. Da mesma forma, Mantins LA, et al. (2020) versaram acerca da importância do aleitamento materno exclusivo até os primeiros seis meses de vida, em três comunidades do estado da Bahia, onde os autores procuram entender os fatores que interferem na prática do aleitamento materno exclusivo a partir da teoria transcultural. 
Diante do exposto, apresenta-se a seguinte questão norteadora: Os aspectos culturais influenciam as puérperas em AME atendidas no ALCON? Assim, a presente pesquisa objetivou entender os aspectos culturais relacionados ao AME em puérperas atendidas no ALCON de um hospital de referência materno infantil do estado do Pará.

\section{MÉTODOS}

A presente pesquisa corresponde a um estudo qualitativo, exploratório e descritivo. Realizado em um hospital de referência materno infantil do estado do Pará. Participaram da pesquisa puérperas admitidas no alojamento (ALCON), tendo em média 60 puérperas/dia e os leitos possuem bastante rotatividade. Entretanto, utilizou-se uma amostra por conveniência de um total de 20 puérperas, sendo 10 de pós-parto vaginal e 10 de pós-parto cesarianos. Este número corresponde a uma projeção feita a partir de estudo realizado no mesmo setor em 2015 (MASCARENHAS ACL, et al., 2015).

Foram incluídas na pesquisa, puérperas internadas no alojamento conjunto, maiores de 18 anos de idade, que estavam em boas condições físicas e mentais. Por sua vez, foram excluídas da pesquisa mulheres menores de 18 anos; que não estavam amamentando por condição clínica/patológica; que estavam realizando procedimentos no momento da pesquisa; que não tivessem completado 48 horas de pós-parto.

Após aplicação de critérios de inclusão e exclusão, foi solicitada a autorização de cada puérpera para realização da entrevista, e posteriormente foi apresentado para as participantes os objetivos da pesquisa e esclarecimentos sobre o Termo de Consentimento Livre e Esclarecido (TCLE) para aquelas que concordaram participar, foi utilizado um smartphone para gravar a entrevista, no qual precisaram assinar um Termo de Gravação de Voz.

Para garantir o anonimato das puérperas, as mesmas foram representadas no texto de acordo com a ordem em que foram entrevistadas, ou seja, a primeira foi representada com o código E1 (primeira entrevistada), a segunda E2, a terceira E3 e etc; de modo a preservar suas identidades, em cumprimento da Resolução 466/2012. Assim, buscou-se garantir o cumprimento da resolução 510/2016, seguindo os princípios éticos da pesquisa possibilitando que a puérpera se sentisse confortável em realizar a entrevista. O projeto foi submetido e aprovado ao Comitê de Ética em Pesquisa (CEP) da Santa Casa, com parecer CEP $n^{\circ} 4.568 .359$.

Destaca-se que a entrevista semiestruturada possibilita a obtenção de dados com maior cobertura, por conta da flexibilidade na interação, torna-se possível corrigir erros de interpretação por parte dos informantes, eliminando respostas equivocadas e, consequentemente, gerando dados mais fidedignos (COSTA WF, et al., 2018).

Nesse sentido, o roteiro semiestruturado para coleta de dados foi constituído por duas sessões, a saber: $\mathrm{Na}$ primeira sessão constituiu-se questões relacionadas à caracterização do perfil sociodemográfico das puérperas, nas quais serviram como variáveis para elaboração do corpus textual. A segunda foi composta de perguntas abertas, buscando obter informações referentes aos aspectos culturais das puérperas em relação ao AME.

Vale ressaltar, que as entrevistas foram realizadas em uma sala reservada para ter maior privacidade, com intuito de deixar a mulher a vontade para responder as perguntas e utilizando as normas de biossegurança para COVID 19, como: higienização das mãos, uso de máscara e álcool em gel.

Para análise dos dados, utilizou-se o software Interface de $R$ pour lês Analyses Multidimensionnelles de Textes et de Questionnaires (IRAMUTEQ). Trata-se de um programa livre que se ancora no software R, e que dá a possibilidade de processamentos e análises estatísticas de textos produzidos, e criado o Corpus Textual após a análise e agrupamento das entrevistas.

Para o tratamento de resultados, foi necessário realizar uma seleção minuciosa das palavras utilizadas pelas puérperas nas entrevistas, pois a seleção de uma palavra com frequência elevada não justifica sua importância para análise dos resultados. 
Diante disso, utilizou-se as técnicas de classificação de análise de similitude, já que esta ferramenta se caracteriza por agrupar e organizar graficamente de acordo com sua frequência, permitindo ao pesquisador identificar e analisar seus dados obtidos a partir do nível da relação de similitude das palavras (CAMARGO BVC; JUSTO AM, 2018)

O estudo se deu pela Análise de Conteúdo, por poder ser esta quantitativa e qualitativa. $\mathrm{Na}$ abordagem quantitativa se traça uma frequência das características (palavras) que se repete no conteúdo do texto. A qualitativa, por sua vez, se considera o conjunto de características em um determinado fragmento do conteúdo (BARDIN L, 2009).

\section{RESULTADOS E DISCUSSÃO}

A partir do software Iramuteq constatou-se que os 20 textos (entrevistas), que compuseram o corpus textual, obtiveram um total de 2.250 ocorrências de palavras (quantidade de palavras contidas no corpus), obtendo média de 127,50 ocorrências por texto.

Ressalta-se que essas ocorrências de palavras se distribuíram em 266 formas. Além disso, no que se refere a porcentagem aponta-se que das 266 palavras que apareceram no corpus, cerca de $40 \%$ (106 formas) tiveram frequência 1 (apareceram apenas uma vez no corpus).

Não obstante, essas palavras com frequência 1, quando comparadas ao total de ocorrências de palavras (2.250), representaram apenas $4,08 \%$, apontando que muitas palavras foram utilizadas apenas uma única vez, e poucas foram utilizadas mais vezes (Gráfico 1).

Gráfico 1 - Ocorrências de palavras de puérperas em AME atendidas no ALCON.

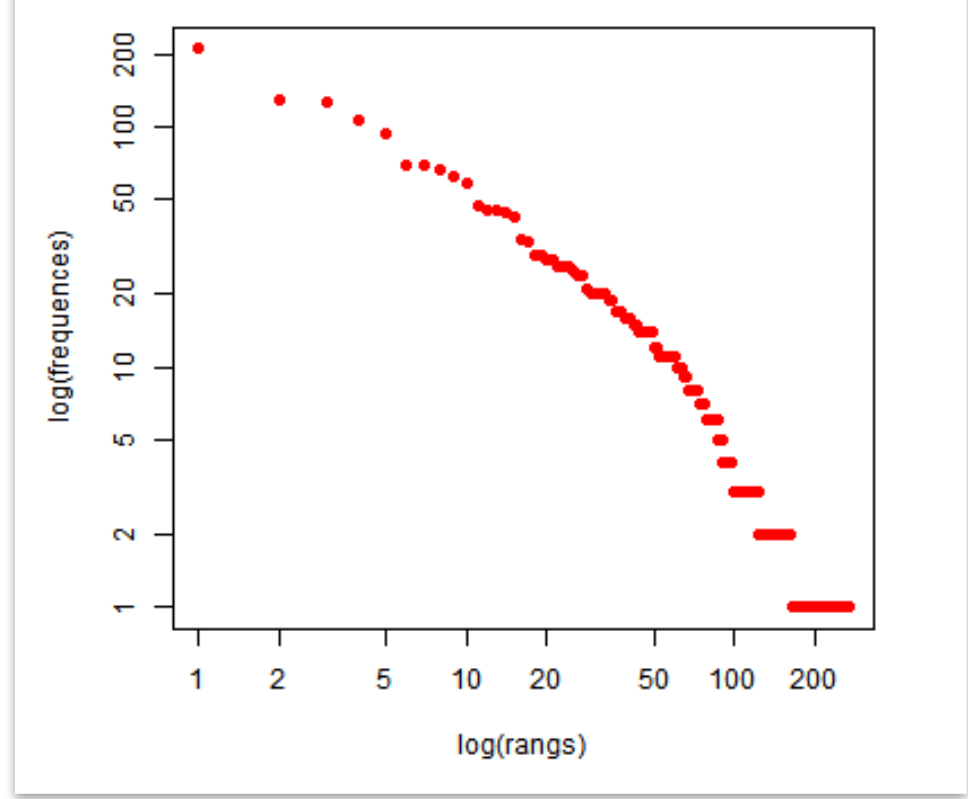

Fonte: Silva FMP, et al., 2021.

Destaca-se que as palavras Mama, Orientar e Não tiveram frequência de 70, 47 e 47 respectivamente. Por outro lado, as palavras volume, possível e permanecer; tiveram frequência 1.

Sobre as informações dos dados sociais de local de nascimento e de residência, destaca-se que, das 20 puérperas, $45 \%$ são naturais de Belém e $50 \%$ residem na capital do estado. No que se refere a idade, a frequência maior foi de 25 anos (4) onde as puérperas com a idade menor foram de 18 anos (3) e a de idade mais elevada foi de 36 anos (1), obtendo dessa forma, uma média de 24 anos.

No que diz respeito a escolaridade, $60 \%$ tinham completado ou estavam cursando o ensino médio; $15 \%$ haviam concluído ou cursando o ensino superior; e $25 \%$ tinham ensino fundamental incompleto. Com relação a ocupação, $60 \%$ declararam-se como donas de casa e as demais alegaram possuir outras ocupações. 
Quando perguntadas sobre o estado civil e religião, $75 \%$ alegaram possuir algum tipo de relacionamento: união estável (10) ou casada (5) e 80\% afirmaram possuir algum tipo de religião: Evangélica (8), Católica (7), Adventista (1).

Para as perguntas que corresponderam aos aspectos culturais relacionados ao Aleitamento Materno, elaborou-se o seguinte grafo de similitude (Figura 1):

Figura 1 - Grafo de similitude proveniente das falas das puérperas em AME atendidas no ALCON.

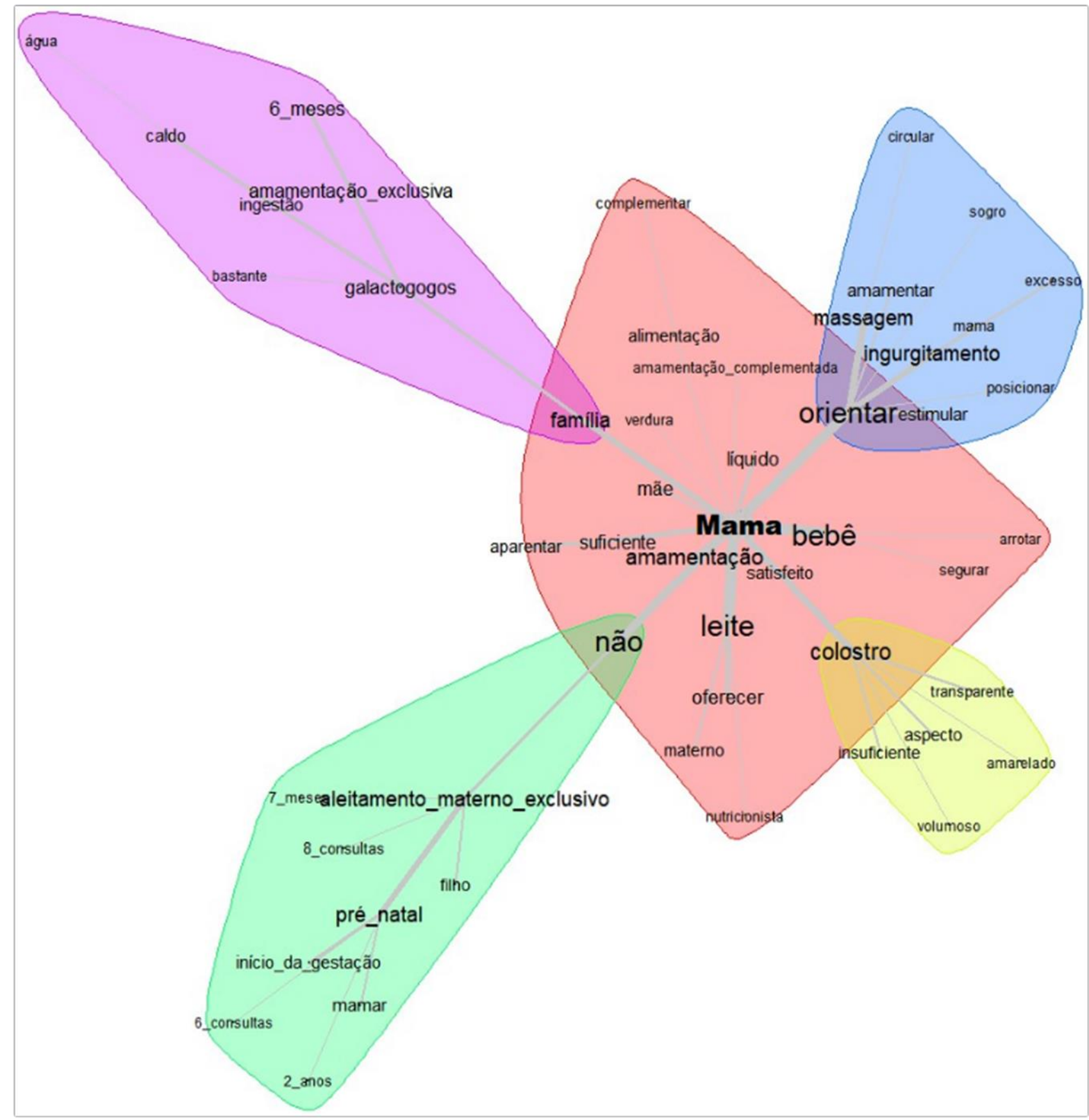

Fonte: Silva, FMP, et al., 2021.

O grafo de similitude destaca a representação de cinco comunidades que foram geradas a partir das ramificações entre as formas, a palavra Mama (frequência 70), gerou ramificações com as palavras Bebê, Leite, Não, Orientar, Colostro, Família; que por sua vez geraram as demais ramificações. Nesse sentido, essas comunidades foram redefinidas em 3 categorias: 


\section{Categoria I: Aspectos relacionados a Amamentação}

A categoria I caracteriza-se por apresentar os aspectos gerais relacionados a amamentação. A palavra Mama possuiu relação de similitude com as palavras Leite, Bebê, Amamentação. A palavra Leite, por sua vez, gerou ramificações com as palavras oferecer, Materno, Nutricionista. Já a palavra Bebê, apresentou ligações com as palavras segurar e arrotar.

Ademais, destaca-se que a palavra Amamentação apresentou relação com as palavras satisfeito, mãe, alimentação e complementar e amamentação complementada, apontando que algumas mães optariam pela amamentação complementada, já que das 20 puérperas no que se refere a ocupação, 12 relataram que eram "donas de casa" e 8 disseram possuir algum emprego fora do seu lar.

Este dado pode ser determinante à interferência na prática do AME ou até mesmo ao desmame precoce, pois quando a puérpera, ao retornar ao seu trabalho, acaba optando em dar outro alimento para suprir o seu bebê, como pode-se observar no relato da E1 que trabalha como operadora de caixa e cursa ensino superior e o da E8 que trabalha como cozinheira:

"Bom, quando estiver estudando, trabalhando ou impossibilitada de amamentar, irei optar por algum leite não materno" (E1).

"Devido ao meu trabalho, pretendo realizar a amamentação complementada" (E8).

Monteiro FR, et al. (2017) destacam que a preocupação relacionada entre amamentação e trabalho materno tornaram-se acentuados na atual conjuntura, em virtude da crescente participação da mulher no mercado de trabalho, pois exige que a mesma tenha que optar em se dedicar ao cuidado do filho ou ter que retornar ao seu trabalho remunerado.

Vale ressaltar que a ocupação exercida pela puérpera pode influenciar negativamente a prática do AME, mas a mãe pode optar na ordenha do leite materno, por possibilitar a garantia da alimentação exclusiva ao bebê quando a puérpera retorna aos seus trabalhos ou estudos.

Macedo CL, et al. (2017) destacam que o processo de ordenha do leite materno, consiste em uma das técnicas de intervenção mais importantes na AME, pois permite com que seja possível prevenir intercorrências mamarias além de garantir a amamentação exclusiva ao bebê.

Não obstante, há desconhecimento dessa técnica por parte das puérperas que acabam, com isso, oferendo alimentos complementares ou o optando pelo desmame precoce. Ao ser perguntada, por exemplo, sobre a ordenha do leite, uma puérpera respondeu:

\footnotetext{
"É a prática de armazenar o leite certo? Eu já ouvir falar, mas ainda não tive o treinamento" (E1).
}

Vale ressaltar, no entanto, que a palavra amamentação exclusiva teve relação de similitude com a palavra seis meses, indicando que quando citadas no texto estavam próximas, como pode-se observar nas respostas iguais das Entrevistadas E10 e E17:

"Até os seis meses de idade, pretendo realizar a amamentação exclusiva" (E10 e E17).

Atrelado a isso, $60 \%$ (12) das puérperas declararam não saber do que se tratava o AME, sendo 6 destas secundigestas, apontando que a experiência obtida conforme o número de gestação não garante que as mesmas tenham o conhecimento da importância da AME.

\section{Categoria II: Aspectos relacionados as orientações durante o pré-natal}

A palavra Não foi a que obteve maior frequência nesta categoria (47), ramificando-se principalmente as palavras Aleitamento materno exclusivo e pré-Natal. Esta última, obteve certa relação com o termo "Início da gestação", indicando que das 20 puérperas entrevistadas, 15 (75\%), responderam que iniciaram o Pré-Natal nos primeiros meses de gestação e as demais alegaram ou ter começado na metade ( 3 puérperas) ou no fim da gestação (2 puérperas). 
No que concerne ao $A M E$, a ramificação com a palavra Não, indica que há certo desconhecimento em relação ao AME por parte das puérperas mesmo estas tendo realizado o pré-natal. Vale ressaltar, no entanto, que $40 \%$ das puérperas alegaram saber sobre o tema, mesmo respondendo de forma direta, como por exemplo, a puérpera E10 que iniciou o pré-natal a partir do terceiro mês de gestação:

"Apenas sei que é a relação da mãe e bebê" (E10).

Ademais, quando perguntadas sobre o conhecimento acerca do Colostro, apenas $15 \%$ (3) disseram não saber do que se tratava o termo. De acordo com Soares e Almeida (2018), entende-se como colostro a primeira secreção das glândulas mamárias, ocorrendo na primeira semana após o parto com volume variando de 2 a $20 \mathrm{ml}$ por mamada nos 3 primeiros dias.

Ressalta-se que a palavra Colostro (frequência 25), gerou ramificações com Transparente, Aspecto, Insuficiente e Volumoso. Indicando que as mães ao explicarem seu conhecimento sobre o assunto, classificavam-no como:

"Um líquido de aspecto transparente (...) acredito que seja insuficiente, pois, no início, o líquido aparenta ser insuficiente para o bebê. Assim, não sei se é possível suprir a alimentação do bebê apenas com o colostro" (E3).

Além disso, ao serem indagadas sobre o mesmo ser suficiente ao bebê, 35\% (7), alegaram ser insuficiente. Destaca-se que das 7 puérperas, apenas uma era primigesta, apontando mais uma vez que quanto maior a experiência da mãe no que se refere ao cuidado de um bebê maior é a tendência de seguir conhecimentos já adquiridos nas gestações anteriores.

Rocha MG e Costa ES (2015), em uma pesquisa realizada com 12 mães em uma Unidade Básica de Saúde de Tauá/CE, destacaram que grande parte das mães que interrompem a amamentação exclusiva, optam por isso por classificarem o leite fraco e insuficiente, sendo o colostro o principal fator de fundamentação das respostas dadas por essas mães, em virtude do seu aspecto.

Diante disso, pode inferir, nas orientações recebidas pelas puérperas não alcançaram os objetivos desejáveis. Destaca-se que durante o pré-natal a explicação da importância do colostro deve ser discutida e constantemente reforçada às puérperas pois quando não explicada de forma adequada pode acarretar no desmame precoce, impossibilitando com isso o AME.

Resultado semelhante foi obtido por Garcez BBD, et al. (2020) que em sua pesquisa realizada com 36 puérperas, em uma unidade materno localizada em Teresina, Piauí, constatou-se que as puérperas possuíam conhecimento regular no que se refere ao aleitamento materno, não tendo obtido orientações durante o período gravídico puerperal.

Da mesma forma, Guimarães DC, et al. (2019), apontaram que as 12 puérperas avaliadasem uma Unidade de Atenção Básica em Montes Claros, Minas Gerais; possuíam considerável conhecimento acerca do aleitamento materno e compreendiam a importância do mesmo à saúde do bebê, mas as poucas orientações recebidas por elas durante o pré-natal poderiam corroborar ao desmame precoce.

Acerca disso, Santos AC e Meireles CP (2021) debruçam-se sobre o olhar humanizado que enfermeiro deve possuir ao realizar as consultas, pois, não basta apenas dizer o que a puérpera deve fazer, ou dizer todos os benefícios que o leite gera ao bebê, mas deve ser o mais sensível possível buscando compreender a realidade da puérpera sobre seu conhecimento acerca dos aspectos da amamentação.

\section{Categoria III: Aspectos relacionados as orientações recebidas pelas puérperas pelos familiares}

A palavra Orientar obteve frequência 47, tendo certa relação de similitude com as palavras Ingurgitamento, Massagem e estimular, indicando que quando era citada no texto estava intimamente conectada com as orientações que as puérperas recebiam em relação ao modo de preparar suas mamas para evitar 0 ingurgitamento.

A palavra Ingurgitamento, esteve interligada com a palavra excesso, apontando que as puérperas, quando entediam do que se tratava o termo, classificavam-no como o "excesso de leito nas mamas". Como se pode observar, por exemplo, na resposta da E13. 
"Acredito que ocorre quando há excesso de leite nos seios" (E13).

Não obstante, apenas uma puérpera alegou que não sabia do que se tratava, mesmo sendo utilizado o termo "Leite empedrado" durante a entrevista. Ademais, das dezenove mães que sabiam do que se tratava, sete alegaram que não receberam qualquer orientação. As mães $E 5$ e E7, por exemplo, quando perguntadas sobre terem recebido orientações responderam: "Não, não recebi nenhuma orientação".

Por outro lado, as puérperas que obtiveram orientações, alegaram que foram guiadas por mães, sogras ou avós, como se pode observar, por exemplo, no relato da E10:

"Eu busco massagear os meus seios para amenizar, tal orientação surgiu da minha avó” (E10).

Destaca-se que o ingurgitamento mamário está relacionado com o início tardio da amamentação, mamadas infrequentes, restrição da duração e frequência das mamadas, uso de suplementos e suç̧ão ineficaz do bebê (FEBRASGO, 2018). Entretanto, quatro puérperas, sendo uma primigesta e três secundigestas, relacionaram este problema com o "arroto do bebê".

A palavra Família (frequência 20), quando citada na entrevista, teve relação de similitude com a palavra galactogogos, indicando certa influência cultural a partir dos conhecimentos familiares.

As puérperas $\mathrm{E} 15$ e E16, por exemplo, quando perguntadas se haviam recebido alguma orientação sobre os galactogogos responderam, respectivamente:

"Sim, as minhas tias recomendaram a ingestão de caldos, sucos e água" (E15).

"A minha sogra orientou a ingestão de bastante líquidos, caldos e água" (E16).

Ferreira TDM, et al. (2018), destacaram a influência familiar, mais especificamente das avós, no processo de AME, destacando que $67,3 \%$ das avós entrevistadas em sua pesquisa entendiam que dar outro tipo de alimento ao bebê era importante. Ademais, a referida pesquisa apontou que as avós entendiam que a amamentação teria que ter um horário específico em virtude de o mesmo corresponder a um alimento fraco.

Ressalta-se que são inúmeros os fatores que interferem na AME ou desmame precoce da puérpera e dentre eles o que se destaca é a interferência cultural que se relaciona com o histórico familiar, como as experiências das avós ou influência de pessoas próximas em seu convívio (BARBOSA DJ, et al., 2020).

Da mesma forma, não se pode justificar a manutenção de conhecimentos culturais a partir do nível de escolaridade, religião ou idade, podendo gerar resultados imprecisos, pois a influência cultural exercida pelos familiares (avós e dos pais) são um dos fatores determinantes para a continuidade da amamentação ou no desmame precoce (MENDES SC, 2019).

As quatro mães, que alegaram possuir ensino superior ou estarem cursando alguma graduação, apontaram não saber do que se tratava pelo menos uns dos temas citados: AME, Colostro, Ingurgitamento. Esse fato revela que os aspectos tradicionais são mantidos mesmo quando há instrução acadêmica. Da mesma forma, no que concerne à influência religiosa, das quatro puérperas que declararam não possuir religião, duas disseram que não sabiam do que se travava o AME, 3 disseram que o colostro era insuficiente ao bebê e quando perguntadas sobre a causa do ingurgitamento, foram unânimes em afirmar que seria pela "falta de amamentação".

A variável idade, também poderia ser apontada como indicador de influência cultural de cada puérpera. Não obstante, diante do emaranhado de idades que as puérperas possuem, destaca-se que há certo grau de similitude entre as respostas das mães de 18, 25 e 36 anos, apontando, portanto, que este argumento é impreciso, pois o fato de uma puérpera possuir 18 anos, não a torna suscetível a receber maior influência cultural.

Assim, reforça-se a possibilidade do enfermeiro durante suas consultas no ALCON, basear-se de acordo com a teoria transcultural, pois deve ser utilizada no sentido de orientar as puérperas no que se refere aos cuidados do seu bebê, mas sem que para isso sejam colocados preconceitos diante dos conhecimentos tradicionais e culturais das puérperas. 


\section{CONCLUSÃO}

O presente estudo possibilitou compreender que mesmo com as orientações obtidas durante o pré-natal os saberes culturais ainda são preservados, pois inúmeras mães ainda têm como referência as orientações de seus familiares. Ademais constatou-se que a ocupação exercida pelas puérperas pode interferir no processo de AME, pois muitas optam em realizar amamentação complementada. Portanto, entende-se que os profissionais de saúde, especificamente os enfermeiros, devem utilizar-se da teoria transcultural ao realizarem orientações quanto ao cuidado do binômio mãe-bebê no ALCON, voltando a realidade de cada puérpera no sentido de fazer com que os saberes tradicionais de cada mãe sejam discutidos e levados em consideração.

\section{REFERÊNCIAS}

1. BARBOSA DJ, et al. Fatores que interferem no aleitamento materno exclusivo durante os primeiros seis meses de vida do bebê. Revista Pró-UniverSUS. 2020; 11(1): 80-87.

2. BARDIN L. Análise de Conteúdo. Lisboa-PO: edições 76, 2009; 229p.

3. BRASIL. Conselho Nacional de Saúde. Resolução n ${ }^{\circ}$ 466, de 12 de dezembro de 2012. Brasília, 2012.

4. BRASIL. Conselho Nacional de Saúde. (2016). Resolução no 510/2016.

5. CAMARGO BVC; JUSTO AM. Tutorial para o uso do software Iramuteq. Laboratório de Psicologia Social da Comunicação e Cognição, Universidade Federal de Santa Catarina, 2018; 19p.

6. COSTA WF, et al. Uso de instrumentos de coleta de dados em pesquisa qualitativa: um estudo em produções científicas de turismo. Turismo- Visão e Ação, Itajaí. 2018; 20(1): 2- 28.

7. FEDERAÇÃO BRASILEIRA DAS ASSOCIAÇÕES DE GINECOLOGIA E OBSTETRÍCIA (FEBRASGO). Amamentação. (Série Orientações e Recomendações FEBRASGO, no. 6/Comissão Nacional Especializada em Aleitamento Materno) São Paulo, 2018; $120 \mathrm{p}$.

8. FERREIRA TDM, et al. Influência das avós no aleitamento materno exclusivo: estudo descritivo transversal. Einstein, 2018; 16 (4): $1-7$.

9. GARCEZ BBD, et al. Avaliação do conhecimento sobre aleitamento materno de primíparas atendidas em uma maternidade de Teresina, Piauí. Revista Eletrônica Acervo Saúde, 202012 (11):1-10.

10. GUIMARÃES DC et al. Conhecimento da puérpera sobre amamentação na Atenção Básica. Revista Eletrônica Acervo Saúde, 2019;18:107-114.

11. LEININGER M. Teoria do cuidado da cultura: uma contribuição importante para o avanço do conhecimento e das práticas transculturais da enfermagem. Revista de enfermagem transcultural. 2002; 13 (3):189-192.

12. LUCENA TS. Práticas de cuidado de puérperas quilombolas à luz da teoria transcultural. Dissertação (Mestrado em Enfermagem) - Escola de Enfermagem e Farmácia, Programa de Pós-Graduação em Enfermagem, Universidade Federal de Alagoas, Maceió, 2019; 96p.

13. MACEDO CL, et al. Técnica de ordenha do leite materno: conhecimento das nutrizes de uma maternidade do Recife. Faculdade Pernambucana de Saúde, Recife, 2017; 25p.

14. MASCARENHAS ACL, et al. A percepção das puérperas frente à atuação do enfermeiro na promoção do aleitamento materno em um hospital amigo da criança do estado do Pará. Revista Paraense de Medicina, 2015; 29(3): 7- 12.

15. MARTINS LA, et al. Prática do aleitamento materno em comunidades quilombolas à luz da teoria transcultural. Revista Brasileira de Enfermagem, 2020; 73 (4): 1-9.

16. MENDES SC et al. Fatores relacionados com uma menor duração total do aleitamento materno. Ciência \& Saúde Coletiva,2019; 24 (5): 1821-1829.

17. MOURA MAV, et al. A teoria transcultural e sua aplicação em algumas pesquisas de enfermagem: uma reflexão. Escola Anna Nery, 2005; 9 (3): 434-440.

18. OLIVEIRA RAM, et al. Aleitamento Materno Exclusivo e introdução de alimentos industrializados nos primeiros dois anos de vida. Multitemas, 2018; 23(54): 47-64.

19. ROCHA MG, COSTA ES. Interrupção precoce do aleitamento materno exclusivo: experiência com mães de crianças em consultas de puericultura. Revista Brasileira em Promoção da Saúde, 2015; 28(4): 547-552.

20. SANTOS AC, MEIRELES CP. A importância da amamentação exclusiva nos seis primeiros meses de vida e o papel da enfermagem. Revista Coleta Científica, 2021; 5(9): 58-69. 